\title{
LAS OBRAS DE ARTE FERROVIARIAS, SU DINÁMICA Y LOS EFECTOS EN LA ACTUALIDAD EN SANTA FE
}

\author{
Raúl Navarro ${ }^{*}$, Patricia Rugge ri, Be lén Alons o, Carla Pagani, Pablo Bussi, Julieta Marcón y \\ Federico Derman
}

Dirección General de Proyectos, Secretaría de Recursos Hídricos (SRH), Ministerio de Infraestructura y Transporte (MIyT), Provincia de Santa Fe, Argentina.

(*)e-mail: rnavarro@santafe.gov.ar - diepros@santafe.gov.ar

\begin{abstract}
RESUMEN
Los terraplenes ferroviarios fueron diseñados respetando los pasos de agua naturales según puede observarse en la ubicación de sus obras de arte. Conjuntamente y motivado por la baja pendiente que las vías requerían dada la gran carga acarreada y las potencias de las máquinas empleadas, tales terraplenes generaron en muchos casos barreras al escurrimiento. Las obras de arte construidas hace un siglo, en muchos casos están desactivadas y es dificultoso detectarlas, esto se ha debido a que el desarrollo posterior no respetó aquellos lineamientos. Las obras de arte fueron desactivadas por falta de limpieza o eliminación debido a la falta de control y a la consecuente falta de conciencia social. En otros casos, las rutas paralelas a las vías, no copiaron los desagües pluviales generando tapones. Así es que pueden detectarse muchos casos en los cuales los lotes de aguas abajo de un terraplén ferroviario, en coincidencia con una obra de arte, no tienen marcada la línea de escurrimiento de salida y los lotes de aguas arriba muestran la presencia de una laguna. Este trabajo presenta algunas problemáticas hídricas de importancia, originadas por la metodología explicada arriba y detectadas durante los años de gestión del equipo de trabajo del Área Proyectos Rosario de la Secretaría de Recursos Hídricos del Ministerio de Infraestructura y Transporte de la Provincia de Santa fe. Se concluye sobre la necesidad de dar un giro en los paradigmas y comenzar a trabajar con la naturaleza y no contra ella.
\end{abstract}

Palabras clave: hidrología superficial, terraplenes ferroviarios, obras de arte, buenas prácticas

\begin{abstract}
Railways were designed in accordance with natural water streams as can be seen in the locations of its work of arts. Low railway slopes due to high weight transported by the convoys were the origin of artificial barriers to the natural flow. Traveling the campaign it can be seen many problems of natural runoff interrupted by locations of work of arts. In many cases, works of art were deactivated by obstruction of it hydraulic section due to lack of cleaning or intentional cut off. It is considered that this fact occurs due to the urban and rural development not has had the same respect to the nature that has had the railways constructors. In other cases, the parallel routes built, not copied the existing drains. So are detected many cases of batches of downstream of a work of art that does not have marked the line upstream runoff observed the presence of a lagoon. This work presents different water issues of importance due to the methodology explained above detected by professionals of the Rosario City Project Area of the Water Resources Secretary depending on Infrastructure and Transport Ministry of Santa Fe Province, Argentina. It is concluded on the need for a shift in paradigms and begins to work with nature and not against it.
\end{abstract}

Keywords: surface hydrology, railway barriers, work of arts, good practices 


\section{INTRODUCCIÓN}

Cuando los ferrocarriles se diseñaron en el siglo XIX, sus proyectistas pensaron a los escurrimientos naturales como una realidad a respetar, lo cual se evidencia en los registros que muestran la ubicación de las obras de arte.

Esta concepción original puede consultarse en la invaluable información que brindan, hoy día, las Cartas Topográficas confeccionadas en la primera mitad del siglo XX por el Instituto Geográfico Militar, hoy Nacional (IGN).

Si comparamos esta documentación con imágenes satelitales de cualquier período desde su aparición, y contrastamos con el inventario de problemáticas hídricas presentes en la Provincia de Santa Fe, veremos que muchas de ellas coinciden geográficamente con la ubicación original de aquellas obras de arte.

Ahora bien, si concurrimos al sitio donde se indica la existencia de una obra de arte determinada, en muchos casos nos será dificultoso detectarla y en otros, imposible.

Esto es debido a que el desarrollo que sucedió a la implantación de los ferrocarriles no tuvo el mismo respeto a los lineamientos básicos mencionados arriba. En muchos casos donde la obra de arte era de pequeña magnitud, debido a su cuenca de aportes o al uso del suelo de la época en que fueron diseñadas, la misma fue lentamente desactivada mediante maniobras de falta de limpieza, favorecimiento del crecimiento de vegetación o cegado o su eliminación. La falta de control sobre las actividades en el territorio favoreció la pérdida de la conciencia social necesaria para entender que de esta manera se estaba perjudicando a propios y vecinos.

En otros casos, la presencia de rutas importantes paralelas a las vías, a medida que fueron siendo pavimentadas, no copiaron los desagües pluviales ferroviarios, habilitaron más aún la modificación de los escurrimientos y en algunos casos dejaron perturbaciones al tránsito del agua demostrando la desaprensión a la problemática hidráulica.

Así es que se detectan muchos casos de lotes ubicados aguas abajo del terraplén ferroviario en coincidencia con una obra de arte indicada en las cartas topográficas que no tienen marcada la línea de escurrimiento que permita el tránsito de los caudales hacia aguas abajo y como contraparte, se puede observar aguas arriba la presencia de una laguna.

\section{OBJETIVO}

El objetivo de este trabajo es poner en consideración una problemática que aunque es muy conocida, no es normalmente enfrentada mediante un planteo que conduzca a la corrección de los efectos negativos que ella acarrea.

Se intenta poner en discusión un criterio de vuelta a las concepciones primigenias mediante las cuales se demostraba respeto por la naturaleza y equidad frente a los inconvenientes que presenta a un propietario la presencia de un bajo natural en su propiedad, el cual también afecta a aquel de aguas arriba como a aquel de aguas abajo.

\section{CASOS}

En la Figura 1 se puede observar la indicación de la presencia de una alcantarilla bajo la vía ferroviaria en una Plancheta (Instituto Geográfico Nacional, 1930). Dicha alcantarilla está ubicada en correspondencia con el bajo que se observa bien marcado por las curvas de nivel cóncavas cuyo nivel va bajando hacia el noreste.

En la Figura 2 se puede observar el funcionamiento hidráulico del bajo en la actualidad, registrado en una imagen satelital (Google Earth, 27/02/201604/05/2017).

Este caso salió a la luz motivado por una denuncia efectuada por los perjudicados de aguas arriba. El análisis de la problemática puso en evidencia irregularidades en la resolución de los drenajes del mencionado bajo.

En la imagen satelital se puede observar que el bajo proveniente desde aguas arriba está muy marcado y que al llegar a la vía férrea forma un área de almacenamiento mostrada por la zona de coloración más oscura y vegetación irregular.

Hacia aguas abajo no se observa la continuación del bajo. Una aproximación de la imagen permitiría detectar un canal paralelo a la vía del ferrocarril que conduce las aguas hacia una alcantarilla ubicada en un cruce a nivel de un camino comunal. 
Como complemento puede indicarse que en la continuidad del bajo hacia aguas abajo, se ha ubicado una zona desarrollada la cual seguramente será afectada por el agua en eventos extremos.

Estas condiciones muestran una evidente inequidad entre los lotes de aguas arriba y aguas abajo. Los primeros se ven perjudicados en mayor medida que lo que lo serían si la obra de arte funcionase adecuadamente y los de aguas abajo reciben un beneficio tal que hasta tienen la posibilidad de poder asentar un área desarrollada con menores riesgos que aquellos naturales que hubiesen tenido, esto a pesar que existen leyes que indicarían la imposibilidad de tal uso del suelo.

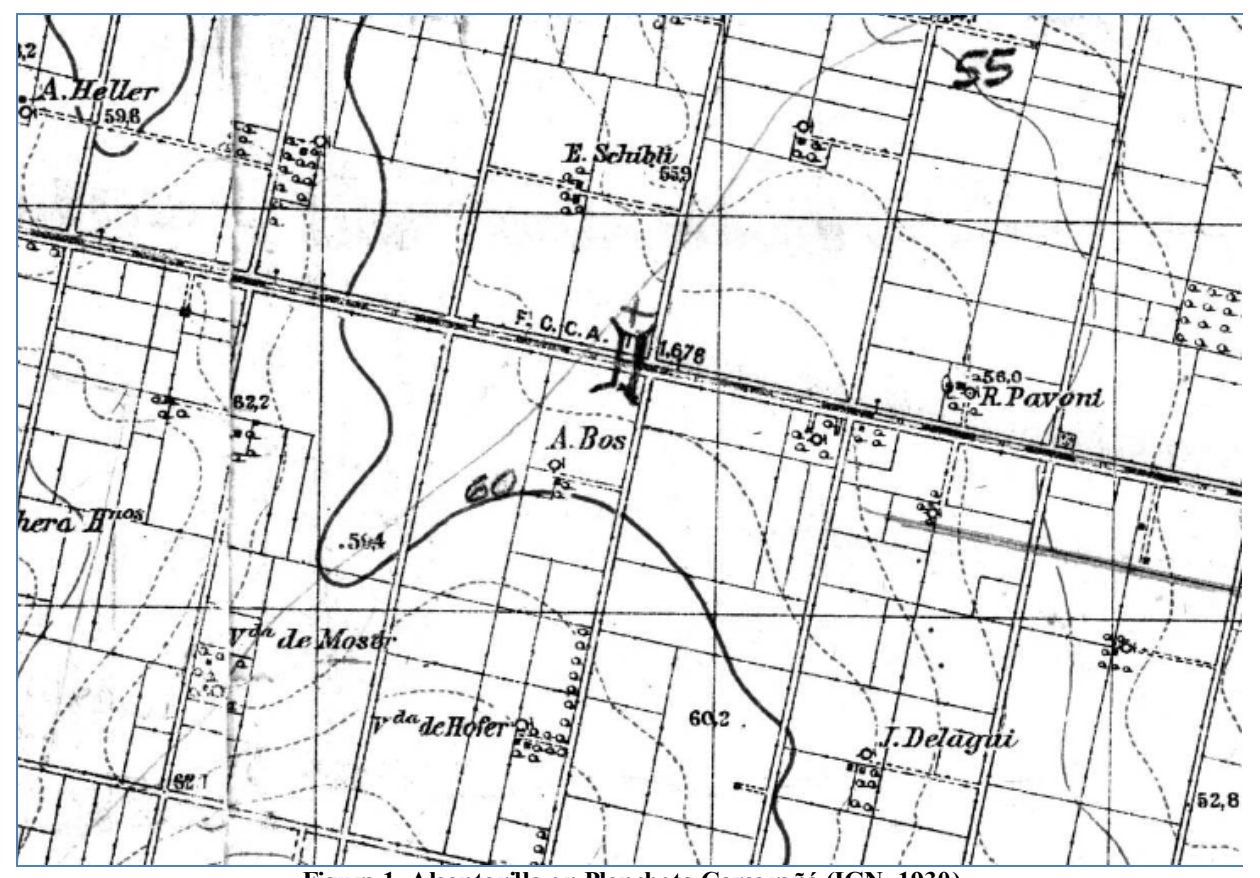

Figura 1. Alcantarilla en Plancheta Carca rañá (IGN, 1930)

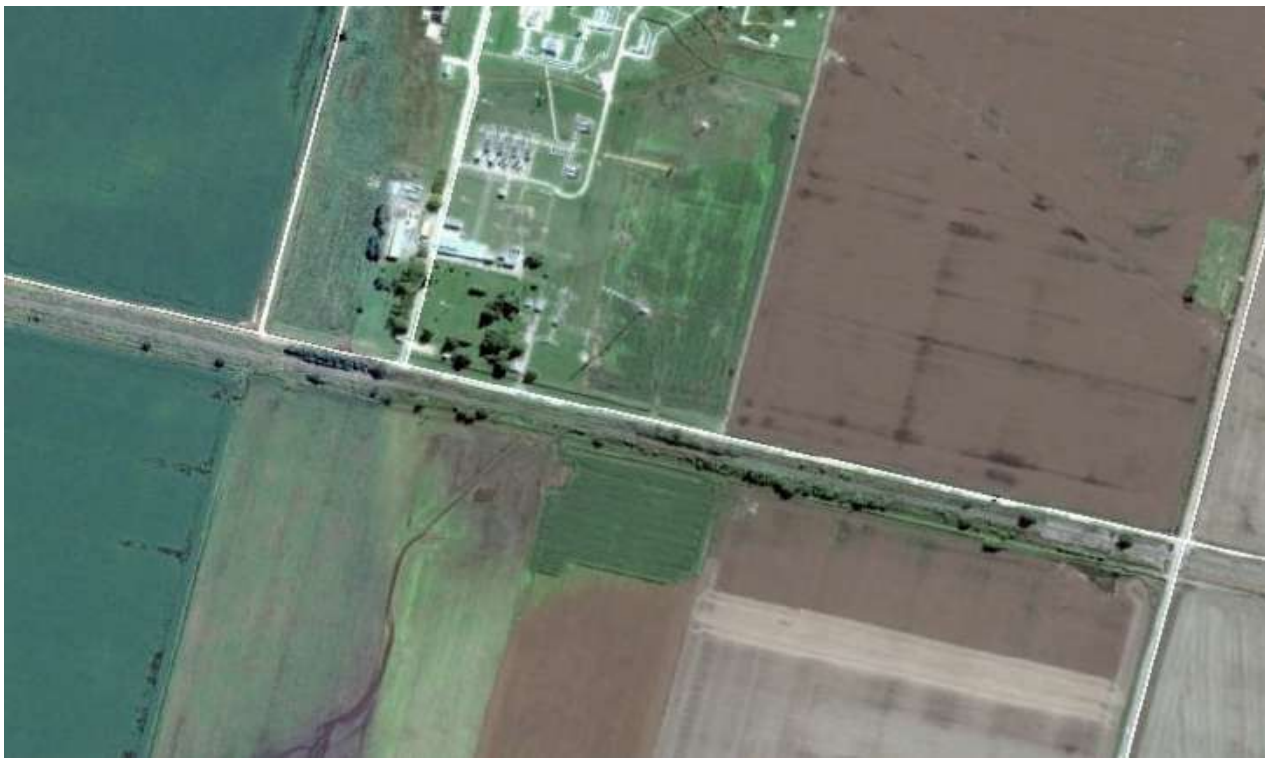

Figura 2. Alcantarilla en imagen sa te lital actual (Google Earth, 27/02/2016-04/05/2017) 
El agravante es que la instalación ubicada aguas abajo fue generada por el Estado Nacional.

Seguramente, estos hechos se producen por una conjunción de acciones e inacciones tanto a nivel público como privado que se pueden clasificar en falta de limpieza ex profeso de los servicios de drenaje o por abandono o acciones de taponamiento de obras de arte o falta de reconstrucción de las mismas cuando fallaron por el solo paso del tiempo

Como ya se mencionó, el desarrollo ubicado aguas abajo, en este caso en particular, fue realizado por el Estado Nacional hace tiempo o en su defecto fue movilizado por el mismo. La ubicación elegida demuestra la falta de consideración de la legislación del Código Civil Argentino (Congreso de la Nación Argentina, 2015).

En dicho Código, el artículo 1975 que se refiere a los obstáculos al curso de las aguas, regula que $l o s$ dueños de inmuebles linderos a un cauce no pueden realizar ninguna obra que altere el curso natural de las aguas o modifique su dirección o velocidad, a menos que sea meramente defensiva; y agrega que si alguno de ellos resulta perjudicado por trabajos del ribereño o de un tercero, puede remover el obstáculo, construir obras defensivas o reparar las destruidas, con el fin de restablecer las aguas a su estado anterior, y reclamar del autor el valor de los gastos necesarios y la indemnización de los demás daños. Si el obstáculo se origina en un caso fortuito, el Estado sólo debe restablecer las aguas a su estado anterior o pagar el valor de los gastos necesarios para hacerlo.

El Código Civil fue modificado en 2015 pero su texto anterior proveniente del siglo XIX rezaba algo similar sobre esta temática.

Este tipo de hechos son muy comunes de encontrar.

En la Figura 3 (Google Earth, 2010) se puede observar otro caso paradigmático en el cual la línea de escurrimiento está canalizada aguas arriba de un camino. Entre dicho camino y la ruta nacional que le sigue aguas abajo y que es paralela a una línea ferroviaria, se observa una mancha de suelo húmedo que indica el almacenamiento que se produce por falta de canalización y de obra de arte de paso. Al encontrarse el agua con la falta de una obra de paso bajo la ruta nacional y bajo el ferrocarril, los escurrimientos se dirigen por las cunetas de dicha ruta y de dicho ferrocarril hasta el cuerpo receptor, que es el Arroyo Ludueña, en una longitud de 3.5 kilómetros aproximadamente encharcándose un tramo de ruta de más de 1.5 kilómetros en eventos por encima de la media y hasta llegándose a cortar por un tiempo del orden del día en los eventos extraordinarios, generando situaciones de sumo riesgo para el tránsito. Siendo esta la principal ruta nacional de comunicación norte sur de la región sur de la provincia, puede tenerse una idea de la magnitud del perjuicio social y económico que genera.

Los dos casos anteriores involucran a una misma empresa concesionaria ferroviaria que tiene importantes intereses económicos regionales y por lo cual cuenta en sus oficinas con personal de la ingeniería civil idónea que conoce la importancia de la problemática y con quien se tiene una relación fluida que permite llegar a soluciones acordadas.

La Dirección Nacional de Vialidad también cuenta con personal idóneo comprometido con la temática pero las decisiones de inversiones al momento de plantearse la necesidad de modificación de las obras de arte pasan por escritorios lejanos en distancia y en afectación y por lo tanto las acciones requeridas tardan mucho más en llegar.

En ambos casos mostrados, si se aplicara la ley provincial No 11730 (Legislatura de la Provincia de Santa Ffe, 2000), de Bienes en Áreas Inundables, se definiría una franja a ambos lados de la línea de escurrimiento dentro de la cual las actividades de desarrollo estarían limitadas y si se aplicase el Código Civil de la República Argentina debería restituirse el paso natural de las aguas bajo la ruta nacional y bajo el ferrocarril.

De las imágenes puede concluirse que los lotes de aguas arriba tienen mayores limitaciones de uso que los de aguas abajo desde el punto de vista productivo. Este hecho es pura y exclusivamente antrópico.

Estas situaciones, totalmente comunes en nuestra región, son de muy difícil modificación, fundamentalmente porque los propietarios que durante muchas décadas han sido beneficiados por estos hechos, consideran que es un derecho adquirido e irrevocable. 


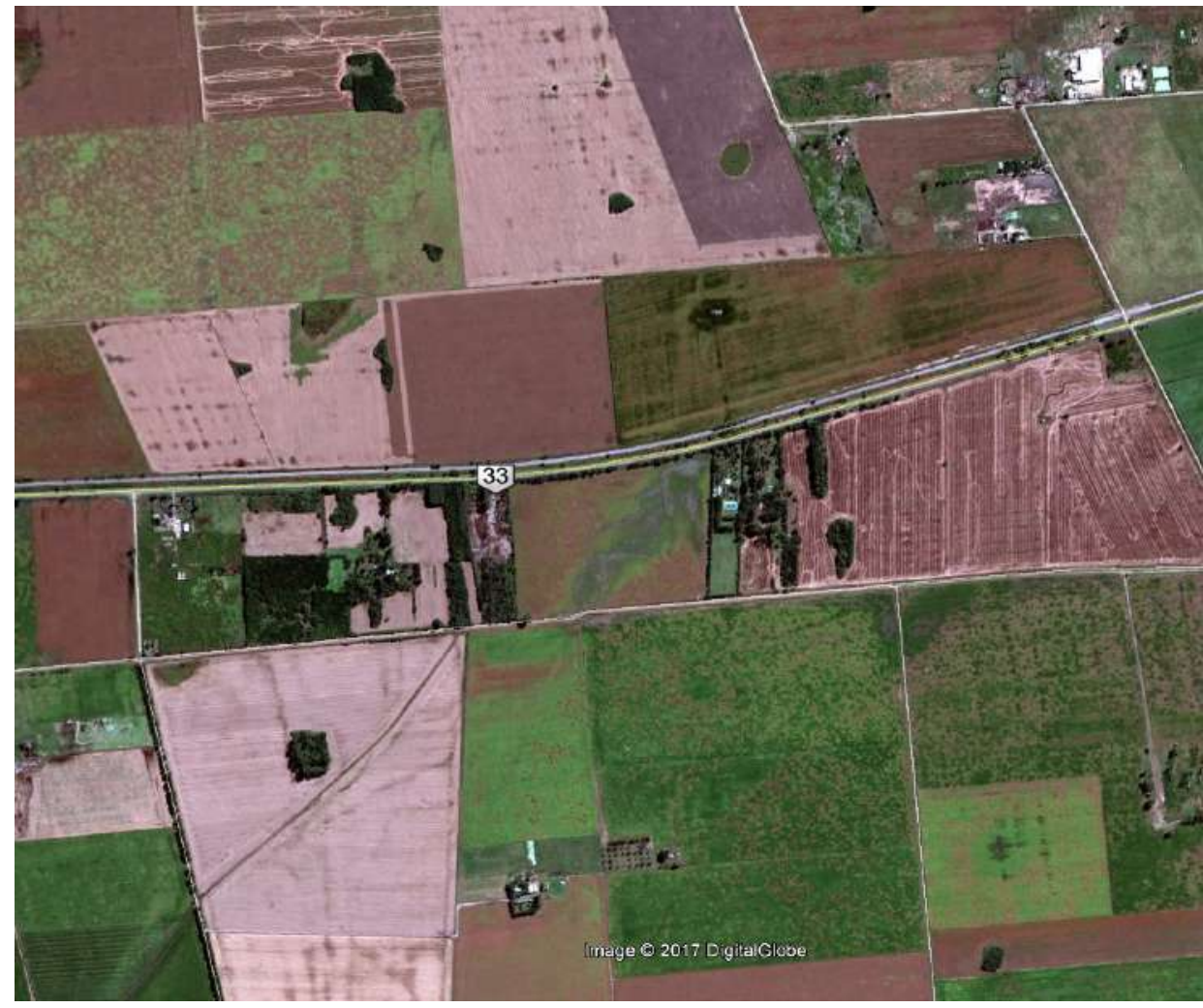

Figura 3. Interrupción de una líne a de escurrimie nto (Google Earth, 22/03/2010)

No solamente para los de los lotes ubicados inmediatamente aguas abajo de la barrera sino para todos aquellos ubicados hacia aguas abajo en la línea de escurrimiento, la idea de modificar esta situación es impensable e inadmisible.

Existen también casos en los que los estamentos provinciales tomaron medidas para mejorar el funcionamiento del bajo natural

Uno de ellos corresponde a un cruce de un bajo natural bajo una vía ferroviaria y bajo un camino comunal existente entre las localidades de Godoy y Rueda en el Departamento Constitución. El bajo natural pertenece a la cuenca del Arroyo Pavón.

Previo a la ejecución de una alcantarilla más grande bajo el camino podía observarse la siguiente situación mostrada en la Figura 4 (Google Earth, 2017).

La figura precedente permite observar como las zonas afectadas por el desborde hacia aguas arriba del bajo natural, ocasionado por la sección hidráulica y las características de diseño de los cabezales de las obras de arte ferroviaria y vial, se extiende hacia el noreste dirigiéndose hacia la localidad de Rueda.

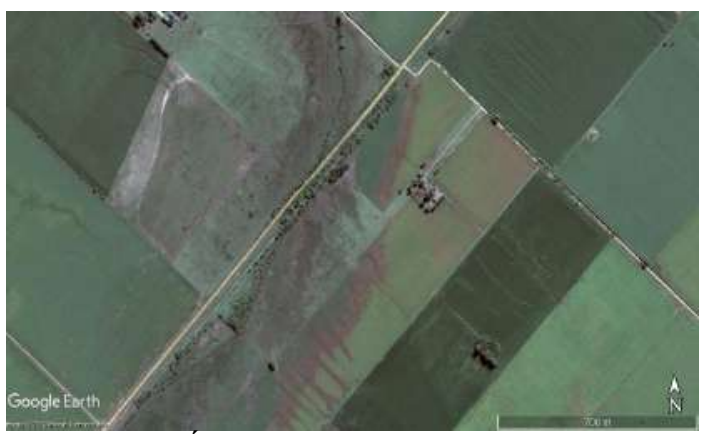

Figura 4. Áre a de desbordes (Google Earth, 2017)

En la Figura 5 se puede observar el detalle de la planimetría de la alcantarilla vial mencionada y la gran profusión de vegetación arbórea existente en una larga franja a ambos lados del bajo. Esta situación también es muy común de encontrar ya que la humedad casi permanente de la zona de bajo permite el crecimiento de árboles los cuáles son de costoso mantenimiento si se los pretendiese podar, más aún cuando se encuentran alejados de las zonas 
urbanas y además son propiciados por los propietarios de aguas abajo a quienes benefician por su control sobre los escurrimientos.

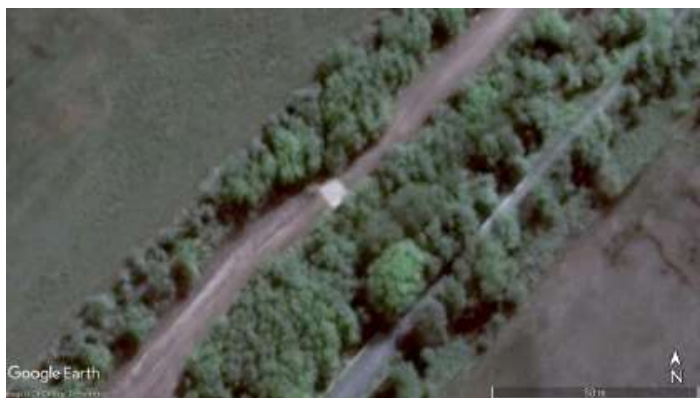

Figura 5. Detalle de alcantarilla (Google Earth, 2017)

La Figura 6 (Google Earth, 2019) muestra los resultados al haberse construido una nueva alcantarilla de mayores dimensiones y con mejores caracterís ticas del diseño hidráulico.

Se observa una reducción en la expansión de la mancha de desborde de aguas arriba de las vías de comunicación.

Sin embargo, no se ha obtenido la mejor respuesta a la acción tomada ya que también se requiere la realización de acciones sobre la alcantarilla ferroviaria y sobre la vegetación arbórea.

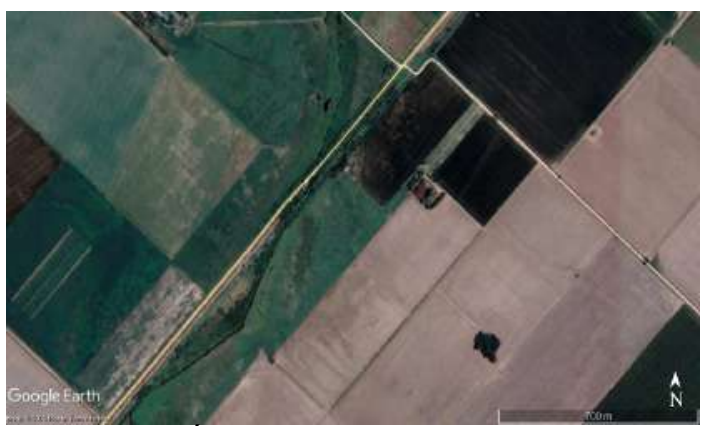

Figura 6. Área de desbordes (Google Earth, 2019)

En la Figura 7 (Google Earth, 2019) puede observarse la magnitud de la ampliación que se llevó a cabo sobre la alcantarilla vial.

En dicha figura puede observarse el ensanche de la luz de la obra de arte y su diseño siguiendo el ángulo de cruce del bajo natural.

La renuencia a socializar los efectos negativos de los desbordes es muy fuerte y debería intentarse vencer la resistencia mediante una presencia más activa de las entidades de control público así como de la toma de medidas correctivas en cada uno de los proyectos de obra que se requieran.

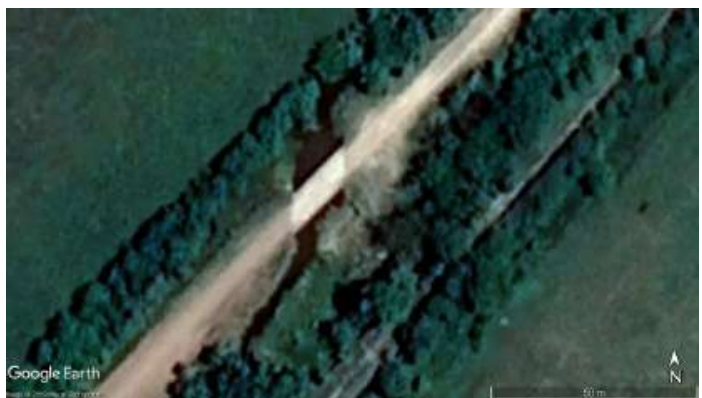

Figura 7. De talle de alcantarilla (Google Earth, 2019)

No se descarta la posibilidad de conducir caudales de bajas recurrencias por cunetas de caminos que disminuyan los efectos negativos sobre las producciones agropecuarias, pero tales acciones siempre deberían tener en cuenta que los aportes de los eventos extraordinarios deberían tomar los caminos que la naturaleza ha marcado antes que el hombre desarrollara su egoísmo en la tierra.

\section{CONCLUSIONES}

La propuesta de este trabajo es concientizar a los tomadores de decisión y planificadores del estado de la necesidad de dar un giro en los paradigmas y comenzar a trabajar con la naturaleza y no contra ella.

Es necesario accionar sobre las barreras que ponen los conceptos tácitos, aplicados para el tratamiento de los problemas de drenajes, que nos separan y modificarlos poco a poco para tornarlos en otros que nos unan y nos ayuden a vivir mejor pensando en el otro.

Hay que empezar por proponerse aplicar las leyes existentes lo cual permitirá detectar la necesidad de ampliarlas o modificarlas de acuerdo a la dinámica que imponen los paradigmas actuales.

Se deben quebrar las inercias que vienen desde décadas atrás y que nos estancan como sociedad.

Hay que atreverse a enfrentar las barreras mentales y favorecer la amplitud de pensamiento.

La conciencia social, bien de difícil acceso en estos momentos, tal vez no nos apoye en la tarea pero el dictado de leyes, su discusión y la puesta en boca de nuevos conceptos pueden a la larga dar algún fruto. 


\section{REFERENCIAS BIBLIOGRÁFICAS}

Congreso de la Nación Argentina (2015). Código Civil y Comercial de la Nación.

Instituto Geográfico Nacional (1960). Cartas Topográficas.

Legislatura de la Provincia de Santa fe (2000). Ley No 11730. "Bienes en Áreas Inundables".

Ministerio de Infraestructura y Transporte (2019).

Gobierno de la Provincia de Santa Fe. Centro de Documentación. Secretaría de Recursos Hídricos.

\section{REGISTRO BIBLIOGRÁFICO:}

Navarro, R., Ruggeri, P., Alonso, B., Pagani, C., Bussi, P., Marcón, J. y Derman, F. (2018). Las obras de arte ferroviarias, su dinámica y los efectos en la actualidad en Santa Fe. Cuadernos del CURIHAM. 24, 51-57. DOI: 10.35305/curiham.v24i0.128

\section{Tipo de Publicación: NOTA TÉCNICA.}

Trabajo recibido el 22/10/2018 y aprobado para su publicación el 02/12/2018. 